\title{
HUBUNGAN REWARD DAN PUNISHMENT DENGAN MOTIVASI KERJA PERAWAT DI RSUD ENCIK MARIYAM
}

\section{Syamsimar}

Program Studi Ilmu Keperawatan Sekolah Tinggi Ilmu Kesehatan Awal Bros Batam Email korespondensi: Samsimarrsem@gmail.com

\begin{abstract}
ABSTRAK
Kualitas kehidupan kerja sangat mempengaruhi kinerja perawat. Buruknya kualitas kehidupan kerja perawat akan turut mempengaruhi motivasi kerja perawat yang merupakan faktor determinan kinerja perawat. Sehingga perlu adanya perhatian khusus dari pihak manajemen mengenai faktor-faktor yang dapat mempengaruhi motivasi kerja perawat, diantaranya yaitu pemberian reward dan punishment. Tujuan penelitian ini adalah mengetahui hubungan reward dan punishment dengan motivasi kerja perawat di RSUD Encik Mariyam tahun 2020. Penelitian yang dilakukan adalah penelitian observasional dengan menggunakan desain deskriptif korelasional dan pendekatan cross-sectional. Metode sampling yang digunakan adalah total sampling dengan besar sample 32 orang perawat di RSUD Encik Mariyam. Data penelitian dikumpulkan melalui metode observasi oleh peneliti dan pengisian kuesioner oleh responden. Data hasil penelitian dianalisa secara univariat dengan tabel frekuensi dan uji bivariate dengan uji Spearman Rho. Hasil analisa univariat didapatkan gambaran reward pada kategori sedang (46.9\%), gambaran punishment pada kategori sedang (59.4\%) dan gambaran motivasi kerja pada kategori sedang (50.0\%). Hasil analisa bivariate variabel reward dengan motivasi didapatkan $p$ value $=0.000$ dan pada variabel punishment dengan motivasi kerja didapatkan $p$ value= 0.001; sehingga dapat disimpulkan ada hubungan yang signifikan antara reward dan punishment dengan motivasi kerja di RSUD Encik Mariyam tahun 2020. Berdasarkan hasil penelitian ini diharapkan agar institusi meningkatkan pengetahuan perawat tentang sistem reward dan punishment yang berlaku melalui seminar/ sosialisasi guna meningkatkan motivasi kerja serta mengendalikan perilaku yang dapat mengurangi efektivitas kinerja perawat.
\end{abstract}

Kata kunci: reward; punishment; motivasi kerja

\section{THE RELATIONSHIP OF REWARD and PUNISHMENT with NURSES' WORK MOTIVATION IN ENCIK MARIYAM GENERAL PUBLIC HOSPITAL}

\begin{abstract}
The quality of work life greatly influences the performance of nurses. The poor quality of nurses' working life will also affect the nurses' work motivation which is a determinant factor in nurse performance. So there needs to be special attention from the management regarding the factors that can influence the nurses' work motivation, including the reward and punishment system. The purpose of this study is to determine the relationship of reward and punishment with the nurses' work motivation at Encik Mariyam General Public Hospital in 2020. The research conducted was an observational study using a descriptive correlational design and cross-sectional approach. The sampling method used
\end{abstract}


was total sampling with a sample of 32 nurses at Encik Mariyam General Public Hospital. Research data were collected through the method of observation by researcher and filling out questionnaires by respondents. The research data were analyzed univariately with a frequency table and bivariate test with the Spearman Rho test. Univariate analysis results showed a medium category of reward (46.9\%), a medium category of punishment (59.4\%) and a medium category of work motivation (50.0\%). The results of the bivariate analysis of reward variables with motivation obtained $p$ value $=0.000$ and the punishment variable with work motivation obtained $p$ value $=0.001$; so it can be concluded that there is a significant relationship between reward and punishment with nurses' work motivation at the Encik Mariyam General Public Hospital in 2020. Based on the results of this study it is hoped that institutions will increase nurses' knowledge of the reward and punishment system that applies through seminars / socialization to improve work motivation and control over work behavior that can reduce the nurse performance.

\section{Keywords: Reward; punishment; motivation}

\section{PENDAHULUAN}

Motivasi adalah tenaga dalam diri individu yang memengaruhi kekuatan atau mengarahkan perilaku. Karena motivasi berasal dari dalam diri seseorang individu, dan manajer tidak dapat secara langsung memotivasi para pegawainya (Lufitasari, 2014). Secara umum perawat memiliki motivasi yang cukup baik untuk bekerja. Mayoritas perawat rumah sakit memiliki motivasi kerja intrinsik yang kuat karena mereka menikmati pekerjaan tersebut, atau karena pekerjaan itu sesuai dengan kebutuhan, nilai, dan tujuan mereka. Faktor-faktor pribadi seperti menjadi lebih terlatih, kebutuhan hidup, kesesuaian dengan nilai-nilai pribadi dapat meningkatkan motivasi kerja perawat. Beberapa faktor organisasi seperti karakteristik tempat kerja, kondisi kerja yang mendukung dan hasil kerja yang optimal juga meningkatkan motivasi kerja perawat. Motivasi kerja perawat (bersama dengan preferensi mereka dan berbagai faktor terkait pekerjaan seperti kondisi kerja dan sistem insentif) memengaruhi perilaku dan kinerja perawat, dan hal ini telah diakui secara luas sebagai salah satu prasyarat untuk praktik keperawatan yang berkualitas, sehingga perlu diberi perhatian lebih dan juga dikelola dengan lebih baik dengan memberi dukungan dalam pencapaian individu, kompetensi, otonomi, dan pelatihan profesional perawat (Toode, 2015).

"Reward adalah usaha menumbuhkan perasaan diterima (diakui) di lingkungan kerja yang menyentuh aspek kompensasi dan aspek hubungan antara para pekerja yang satu dengan yang lainnya" (Febrianti, 2014). Punishment adalah tindakan yang dirancang untuk mengurangi perilaku yang tidak diinginkan dengan menciptakan konsekuensi 
negatif untuk individu yang melakukannya (Newel, 2014). Tujuan dari pemberian punishment adalah agar pegawai yang telah melanggar peraturan merasa jera dan tidak akan mengulangi lagi pelanggaran tersebut (Tangkuman, 2015).

\section{"Reward dan punishment sama-sama dibutuhkan untuk merangsang perawat agar meningkatkan kualitas kerja dan memiliki motivasi yang tinggi dalam melakukan pekerjaannya. Kedua sistem tersebut digunakan sebagai bentuk reaksi pemimpin tehadap kinerja para bawahannya. Meskipun sekilas fungsi dari reward dan punishment berlawanan, namun pada dasarnya reward dan punishment sama-sama memiliki tujuan agar seseorang menjadi lebih baik, lebih berkualitas, dan lebih bertanggung jawab terhdap tugas yang diberikan kepadanya" (Novalia, 2017).}

Perawat mengabdikan waktu, tenaga, waktu, pengetahuan dan keterampilannya dalam membantu mencapai tujuan rumah sakit, "maka setiap perawat layak untuk mendapatkan imbalan dan kompensasi sebagai reward atas apa yang telah dihasilkan. Pemberian insentif jasa perawat merupakan bagian dari sistem remunerisasi atau manajemen imbalan di rumah sakit. Tujuan mendasar dari semua program insentif adalah memberikan imbalan kepada seseorang atas sesuatu yang secara persis telah dihasilkannya. Untuk meningkatkan kesejahteraan dan memotivasi kerja perawat, maka rumah sakit memberikan kompensasi finansial langsung berupa gaji dan tunjangan insentif jasa pelayanan keperawatan yang dibagikan setiap bulan. Namun demikian, sistem pemberian jasa perawat yang ada saat ini tampaknya masih belum mampu secara maksimal meningkatkan motivasi kerja perawat" (Awan, 2014).

Kondisi kerja perawat Indonesia saat ini masih belum memuaskan, hal ini dapat dilihat dari rendahnya sistem reward rumah sakit negeri dari pada rumah sakit swasta, yang secara otomatis mempengaruhi mutu pelayanan rumah sakit. Berdasarkan studi awal yang telah dilakukan peneliti dengan metode wawancara pada 6 orang perawat pada tanggal 13 Oktober 2019 di RSUD Encik Mariyam, dimana 2 orang perawat mengatakan bahwa motovasi kerja perawat sudah dapat dikatakan cukup, hal ini dikarenakan sudah pernah diadakannya penilaian seperti perawat terbaik di RSUD Encik Mariyam dan memberikan reward kepadanya dengan harapan dapat memotivasi individu dalam meningkatkan kinerjanya. Reward diberikan berupa hadiah ,kenaikan pangkat, golongan atau level klinis yang berpengaruh terhadap insentif antara lain jasa medis. Reward diberikan berdasarkan pertimbangan pihak mmanajemen. Akan tetapi 4 orang perawat mengatakan motivasi kerja perawat masih kurang karena masih ditemukan perawat yang tidak mengindahkan aturan yang berlaku.

\section{METODE PENELITIAN}

Rancang penelitian observasional ini menggunakan desain deskriptif korelasional dan pendekatan crosssectional. Tekhnik sampling yang digunakan adalah total sampling dengan besar sampel yang digunakan sebanyak 32 responden yang 
merupakan perawat di RSUD Encik

Maryam. Pengumpulan data

dilakukan dengan pengisian kuesioner. Hasil penelitian dianalisa dengan uji Spearman rho dengan nilai kemaknaan $0.05 \%$.

\section{HASIL DAN PEMBAHASAN}

\section{Analisa Univariat}

Tabel 1

Distribusi frekuensi karakteristik responden, reward, punishment, dan motivasi kerja perawat $(n=32)$

\begin{tabular}{|c|c|c|c|}
\hline No & Karakteristik & $\mathrm{f}$ & $\%$ \\
\hline \multirow[t]{3}{*}{1} & Jenis kelamin & & \\
\hline & Laki-laki & 9 & 28.1 \\
\hline & Perempuan & 23 & 71.9 \\
\hline \multirow[t]{5}{*}{2} & Umur & & \\
\hline & $<25$ tahun & 2 & 6.25 \\
\hline & 26-35 tahun & 18 & 56.25 \\
\hline & 36-45 tahun & 10 & 31.25 \\
\hline & $>46$ tahun & 2 & 6.25 \\
\hline \multirow[t]{5}{*}{3} & Pendidikan & & \\
\hline & DIII Kep/ Keb & 21 & 65.6 \\
\hline & DIV Kep/ Keb & 4 & 12.5 \\
\hline & S1 Kep & 5 & 15.6 \\
\hline & Ners & 2 & 6.3 \\
\hline \multirow[t]{5}{*}{4} & Masa kerja & & \\
\hline & $<1$ tahun & 3 & 9.4 \\
\hline & 1-5 tahun & 13 & 40.6 \\
\hline & 6-10 tahun & 12 & 37.5 \\
\hline & $>10$ tahun & 4 & 12.5 \\
\hline \multirow[t]{4}{*}{5} & Reward & & \\
\hline & Rendah & 9 & 28.1 \\
\hline & Sedang & 15 & 46.9 \\
\hline & Tinggi & 8 & 25.0 \\
\hline \multirow[t]{4}{*}{6} & Punishment & & \\
\hline & Rendah & 6 & 18.8 \\
\hline & Sedang & 19 & 59.4 \\
\hline & Tinggi & 7 & 21.9 \\
\hline \multirow[t]{4}{*}{7} & Motivasi & & \\
\hline & Rendah & 7 & 21.9 \\
\hline & Sedang & 16 & 50.0 \\
\hline & Tinggi & 9 & 28.1 \\
\hline
\end{tabular}

Berdasarkan tabel 1 diatas diketahui mayoritas responden adalah perempuan $(71.9 \%)$ dan lebih dari setengahnya berusia antara 26-35 
tahun (56.25\%); lebih dari setengah responden dengan latar belakang pendidikan DIII Keperawatan/ Kebidanan (65.6\%); hampir setengah responden memiliki masa kerja antara 1-5 tahun (40.6\%).

Pada tabel diatas diketahui hampir setengah jumlah responden memiliki persepsi reward pada kategori sedang (46.9\%). "Pemberian reward atau penghargaan kepada perawat yang berprestasi dapat memberikan dorongan kepada perawat untuk lebih meningkatkan produktivitasnya dalam bekerja. Perawat yang produktif akan dapat meningkatkan mutu dan kualitas rumah sakit". Gambaran persepsi penerimaan reward oleh perawat menunjukkan lebih dari separuh responden memilih 'tidak setuju' pada item pernyataan 'Saya diberikan kesempatan untuk berkembang (promosi) apabila saya berprestasi' sedangkan pada item pernyataan lain jawaban bervariasi namun cenderung pada rentang positif (sangat setuju sekali, sangat setuju, atau netral). Hal tersebut memberi gambaran instansi kurang memberi penghargaan terhadap prestasi yang di capai oleh perawat, atau instansi memberikan penghargaan namun dalam wujud yang tidak sesuai harapan perawat.

Diketahui lebih dari setengah responden memiliki persepsi punishment pada ketogori sedang (59.4\%). Sistem punishment yang diterapkan di RSUD Encik Mariyam saat ini terdiri dari beberapa tahapan seperti "nasehat/arahan oleh kepala ruangan, teguran, pemberian surat peringatan, pemberian denda/ pemotongan insentif hingga pada tahap skors/pemberhentian kerja sesuai dengan besar pelanggaran yang dilakukan. Keseluruhan sistem punishment tersebut telah berjalan dan diterapkan", namun terdapat variasi dalam tanggapan perawat terkait pelaksanaan punishment tersebut. Pemberian punishment terutama pada tahap awal seperti arahan/ teguran perlu memperhatikan aspek individu dan penyebab terjadinya kelalaian, punishment seyogyanya tidak bersifat mempermalukan, dan baiknya dilakukan dengan tetap mengutamakan privasi tiap-tiap individu.

Setengah dari jumlah responden diketahui memiliki motivasi pada kategori sedang (50\%). "Motivasi adalah faktor yang kehadirannya dapat menimbulkan kepuasan kerja dan meningkatkan produktivitas atau hasil kerja dan menimbulkan berbagai perilaku manusia". Upaya yang dilakukan untuk meningkatkan motivasi sejatinya adalah upaya upaya untuk meningkatkan kinerja. Pada hasil penelitian ini proporsi motivasi kerja perawat didominasi oleh kategori sedang. Hal ini dapat dipengaruhi oleh persepsi faktorfaktor yang mempengaruhi motivasi kerja yang juga pada kategori sedang. Penilaian yang dilakukan juga mengaitkan motivasi kerja dengan faktor pendukung nya seperti tanggungjawab, persepsi penerimaan pengakuan oleh atasan, komitmen pemimpin, insentif dan kondisi kerja. 


\section{Analisa Bivariat}

a. Hubungan reward dengan motivasi kerja perawat

Tabel 2

Tabel silang reward dan motivasi kerja

\begin{tabular}{|c|c|c|c|c|}
\hline \multirow{2}{*}{ Reward } & \multicolumn{3}{|c|}{ Motivasi } & \multirow{2}{*}{ Total } \\
\hline & Rendah & Sedang & Tinggi & \\
\hline \multirow{2}{*}{ Rendah } & 6 & 2 & 1 & 9 \\
\hline & $18.8 \%$ & $6.3 \%$ & $3.1 \%$ & $28.1 \%$ \\
\hline \multirow{2}{*}{ Sedang } & 1 & 14 & 0 & 15 \\
\hline & $3.1 \%$ & $43.8 \%$ & $0.0 \%$ & $46.9 \%$ \\
\hline \multirow{2}{*}{ Tinggi } & 0 & 0 & 8 & 8 \\
\hline & $0.0 \%$ & $0.0 \%$ & $25.0 \%$ & $25.0 \%$ \\
\hline \multirow{2}{*}{ Total } & 7 & 16 & 9 & 32 \\
\hline & $21.9 \%$ & $50.0 \%$ & $28.1 \%$ & $100.0 \%$ \\
\hline
\end{tabular}

Pada tabel 2 diketahui hampir separuh data responden mempunyai persepsi reward kategori sedang dan motivasi kategori sedang (43.8\%). Hasil analisis hubungan reward dengan motivasi kerja perawat dengan nilai signifikansi sebesar $0.000(\mathrm{p}$ value $=0.000)$ dimana pada taraf signifikansi $5 \%, \mathrm{p}<0.05$ dapat disimpulkan ada hubungan yang signifikan antara reward dan motivasi kerja perawat di RSUD Encik Mariyam. Nilai korelasi $\mathrm{r}=$ 0.794 yang berarti terdapat korelasi kuat antara reward dan motivasi kerja perawat.

"Sistem imbalan atau reward dirancang oleh perusahaan bertujuan untuk memacu gairah kerja para karyawannya supaya dapat meningkatkan prestasinya dalam bekerja. Berdasarkan hasil penelitian diatas dapat dikatakan bahwa motivasi kerja karyawan akan terbentuk dengan adanya reward baik yang berasal dari gaji, tunjangan, bonus, penghargaan interpersonal, pencapaian (achievement), maupun dari otonomi, sehingga dapat disimpulkan bahwa terdapat pengaruh signifikan antara kedua variable".

"Pegawai menginginkan penghargaan yang setimpal dengan apa yang diberikannya kepada perusahaan dan sama dengan yang diterima pegawai lain dengan pekerjaan serupa, apabila terpenuhi, pegawai tersebut akan menunjukkan hasil kerja yang konsisten. Norma ekuitas adalah hal yang penting bagi sistem penghargaan. Jika pegawai tidak memperolehnya, maka cenderung akan mengurangi sumbangsih mereka atau bahkan keluar dari perusahaan tersebut. Jadi pada aspek yang lebih luas, sistem penghargaan dirancang supaya mampu menarik perhatian, mempertahankan dan mendorong pegawaiagar bekerja lebih produktif. Dimana sistem penghargaan harus mencerminkan win-win result, bagi pegawai dan perusahaan".

Reward merupakan suatu cara untuk "meningkatkan motivasi 
kerja karyawan dan perilaku seseorang sehingga dapat mempercepat pelaksanaan pekerjaan yang dibebankan dan pada akhirnya target atau tujuan yang ingin dicapai dapat terlaksana dengan baik. Reward merupakan suatu sarana motivasi atau sarana yang dapat menimbulkan dorongan dan merupakan salah satu jenis penghargaan yang dikaitkan dengan prestasi kerja, yang diberikan dalam bentuk uang atau penghargaan yang ditetapkan berdasarkan prestasi, semakin tinggi prestasi kerjanya, semakin besar pula reward yang diberikan. Reward juga diartikan sebagai ganjaran, hadiah, penghargaan atau imbalan. Dalam konsep manajemen, reward merupakan salah satu alat untuk peningkatan motivasi para karyawan".

Beberapa penelitan sebelumnya juga menghasilkan kesimpulan yang sejalan dengan hasil penilaian ini dimana pemberian reward secara signifikan mempengaruhi motivasi kerja karyawan. Penelitian Novalia (2017) tentang reward dan punishment dengan motivasi mengikuti handover perawat di ruang rawat inap, didapatkan kesimpulan adanya hubungan yang signifikan antara kedua variabel, hasil tabulasi silang menunjukkan hampir setengah responden mempersepsikan penerimaan reward yang tinggi, dan memiliki motivasi tinggi, hasil analisa bivariate menunjukkan nilai signifikansi $\mathrm{p}$ value $=0.013$ sehingga dapat disimpulkan hubungan kedua variabel tersebut adalah signifikan.
Berdasarkan hipotesis pertama reward berhubungan dengan motivasi kerja perawat. "Hal ini bisa disebabkan adanya aspekaspek/ indikator -indikator yang berkaitan dengan reward yang memberikan dampak terhadap motivasi kerja. Aspek-aspek tersebut diantaranya adalah: gaji tetap, insentif, bonus, penghargaan, pelatihan, tunjangan, asuransi, serta promosi. Motivasi kebutuhan akan berafiliasi dan kebutuhan akan berprestasi. Pada dasarnya reward adalah usaha menumbuhkan perasaan diterima (diakui) dilingkungan kerja, yang menyentuh aspek kompensasi dan aspek hubungan antara pekerja yang satu dengan yang lainnya".

Adanya hubungan juga memberikan gambaran mengenai kemampuan manajemen untuk mempertahanakan keberadaan karyawan khususnya perawat di rumah sakit tersebut, "besarnya reward dapat diartikan sebagai besarnya penghargaan perawat. Besarnya reward juga menunjukkan jaminan yang diberikan kepada perawat agar bekerja sesuai dengan ketentuan yang telah ditetapkan. Reward merupakan suatu cara untuk meningkatkan motivasi kerja perawat dan perilaku seseorang sehingga dapat mempercepat pelaksanaan pekerjaan yang dibebankan dan pada akhirnya target atau tujuan yang ingin dicapai dapat terlaksana dengan baik. Reward merupakan suatu sarana motivasi atau sarana yang dapat menimbulkan dorongan dan merupakan salah satu jenis penghargaan yang dikaitkan dengan prestasi kerja, yang 
diberikan dalam bentuk uang atau penghargaan yang ditetapkan berdasarkan prestasi, semakin tinggi prestasi kerjanya, semakin besar pula reward yang diberikan".

b. Hubungan punishment dengan motivasi kerja perawat

Tabel 3

Tabel silang punishment dengan motivasi kerja perawat

\begin{tabular}{|c|c|c|c|c|}
\hline \multirow{2}{*}{ Punishment } & \multicolumn{3}{|c|}{ Motivasi } & \multirow{2}{*}{ Total } \\
\hline & Rendah & Sedang & Tinggi & \\
\hline \multirow{2}{*}{ Rendah } & 4 & 2 & 0 & 6 \\
\hline & $12.5 \%$ & $6.3 \%$ & $0.0 \%$ & $18.8 \%$ \\
\hline \multirow{2}{*}{ Sedang } & 3 & 11 & 5 & 19 \\
\hline & $3.1 \%$ & $34.4 \%$ & $15.6 \%$ & $59.4 \%$ \\
\hline \multirow{2}{*}{ Tinggi } & 0 & 3 & 4 & 7 \\
\hline & $0.0 \%$ & $9.4 \%$ & $12.5 \%$ & $21.9 \%$ \\
\hline \multirow{2}{*}{ Total } & 7 & 16 & 9 & 32 \\
\hline & $21.9 \%$ & $50.0 \%$ & $28.1 \%$ & $100.0 \%$ \\
\hline
\end{tabular}

Berdasarkan hasil tabel silang pada tabel 3 diatas dapat diketahui sebagian responden mempunyai persepsi punishment sedang dan motivasi sedang $(34.4 \%)$. Hasil analisis hubungan punishment dan motivasi kerja perawat dengan nilai signifikansi sebesar $0.001(\mathrm{p}$ value $=0.001)$ dimana pada taraf signifikansi $5 \%, \mathrm{p}<0.05$ dapat disimpulkan ada hubungan yang signifikan antara punishment dan motivasi kerja perawat di RSUD Encik Mariyam. Nilai korelasi $\mathrm{r}=$ 0.548 yang berarti terdapat korelasi sedang antara punishment dan motivasi kerja perawat.

Punishment atau hukuman merupakan konsekuensi yang tidak menyenangkan atau tidak diinginkan sebagai hasil dari dilakukannya perilaku tertentu. Punishment sebagai suatu perbuatan yang kurang menyenangkan yang diberikan kepada karyawan ketika terjadi pelanggaran justru merupakan sesuatu yang baik. "Punishment merupakan ancaman hukuman yang bertujuan untuk memperbaiki karyawan pelanggar, memelihara peraturan yang berlaku dan memberikan pelajaran kepada pelanggar. Secara umum pemberian punishment pada karyawan bertujuan untuk meningkatkan motivasi kerja karyawan sehingga seorang karyawan akan maksimal dalam bekerja. Punishment dimunculkan bagi seorang karyawan yang melakukan kesalahan dan pelanggaran agar termotivasi untuk menghentikan perilaku menyimpang dan mengarahkan pada perilaku positif".

Hukuman (punishment) adalah sebuah cara untuk mengarahkan sebuah tingkah laku agar sesuai dengan tingkah laku yang berlaku secara umum. "Dalam hal ini, hukuman diberikan ketika sebuah tingkah laku yang tidak diinginkan ditampilkan oleh orang yang bersangkutan atau orang yang bersangkutan tidak memberikan 
reaksi atau tidak menampilkan sebuah tingkah laku yang diinginkan. Dalam menjalankan organisasi diperlukan sebuah aturan dan hukum yang berfungsi sebagai alat pengendali agar kinerja pada organisasi tersebut dapat berjalan dengan baik. Jika aturan dan hukum dalam suatu organisasi tidak berjalan baik maka akan terjadi konflik kepentingan baik antar individu maupun antar organisasi. Pada keadaan tertentu, pemberian sangsi dapat lebih efektif untuk merubah perilaku pegawai, yaitu dengan mempertimbangkan: waktu, intensitas, jadwal, klarifikasi, dan impersonalitas (tidak bersifat pribadi). Upaya perusahaan dengan memberikan hukuman (punishment) dilakukan untuk memberikan motivasi karyawan agar bekerja sesuai dengan ketentuan yang telah ditetapkan”.

Beberapa penelitian terkait sebelumnya juga menunjukkan kesesuaian dengan hasil penelitian ini dan pandangan-pandangan teori diatas. Hasil penelitian Sandy (2017) tentang pengaruh reward dan punishment serta rotasi pekerjaan terhadap motivasi kerja untuk meningkatkan kinerja karyawan hotel di Jember menunjukkan bahwa "variabel reward dan punishment, rotasi pekerjaan memiliki pengaruh positif dan signifikan terhadap motivasi kerja secara parsial, variabel reward dan punishment, rotasi pekerjaan memiliki pengaruh positif dan signifikan terhadap kinerja pegawai secara parsial, variabel reward dan punishment, rotasi pekerjaan dan motivasi kerja secara simultan berpengaruh secara positip dan signifikan terhadap kinerja karyawan". Penelitian lainnya oleh Novelia (2017) tentang "reward dan punishment dengan motivasi mengikuti handover di ruang rawat inap menyimpulkan hubungan antara punishment $(\mathrm{p}$-value $=0,006)$ dengan motivasi mengikuti handover perawat diruang rawat inap Rumah Sakit Umum Daerah dr. Zainoel Abidin Banda Aceh".

Hasil analisis dapat diketahui bahwa terdapat "pengaruh signifikan antara punishment terhadap motivasi kerja karyawan. Hasil tersebut menunjukkan adanya peningkatan atau semakin tingginya punishment maka motivasi kerja karyawan akan mengalami peningkatan. Peningkatan punishment tersebut yaitu mengenai usaha meminimalisir kesalahan yang akan terjadi, adanya hukuman yang lebih berat bila kesalahan yang sama dilakukan, hukuman diberikan dengan adanya penjelasan dan hukuman segera diberikan setelah terbukti adanya penyimpangan maka motivasi kerja karyawan akan mengalami peningkatan".

Hasil analisis juga menunjukkan bahwa dengan kebijakan mengenai punishment khususnya yang bersifat preventif memberikan dukungan untuk meningkatkan motivasi kerja para karyawan, dimana punishment preventif memotivasi perawat untuk mengerjakan tugas-tugas sesuai dengan aturan yang berlaku. Dimana dalam hal ini perawat lebih suka apabila punishment yang berlaku bersifat tegas dan 
diberlakukan secara adil kepada seluruh staf. Aturan-aturan yang kurang tegas, bermakna ganda, atau tidak disosialisasikan dengan baik cenderung menurunkan motivasi perawat atau memberikan celah untuk mangkir dari punishment yang berlaku.

\section{SIMPULAN}

1. Hampir setengah dari jumlah responden $(46.9 \%)$ memiliki persepsi reward pada kategori sedang.

2. Lebih dari setengah responden (59.4\%) memiliki persepsi punishment pada ketogori sedang.

3. Setengah dari jumlah responden (50\%) memiliki motivasi pada kategori sedang.

4. Ada hubungan yang signifikan antara reward dan motivasi kerja perawat di RSUD Encik Mariyam

5. Ada hubungan yang signifikan antara punishment dan motivasi kerja perawat di RSUD Encik Mariyam

\section{UCAPAN TERIMAKASIH}

1. Bapak Prof. Dr. Fadil Oenzil, PhD. Sp.GK selaku Ketua Stikes Awal bros Batam;

2. Ibu Ns. Sri Muharni, S.Kep., M.Kep selaku Ka. Prodi Sarjana Keperawatan Stikes Awal bros Batam

3. Ibu Sri Muharni, Ners, M.Kep selaku pembimbing I yang telah membimbing dan mengarahkan saya dalam menyusun proposal skripsi S1 Keperawatan Stikes Awalbross Batam.

4. Ibu Utari Christya Wardhani, Ners,M.Kep selaku pembimbing II yang telah membimbing dan mengarahkan saya dalam menyusun proposal skripsi S1 Keperawatan Stikes Awalbross Batam.

5. Bapak dr. Suryadi selaku direktur RSUD Encik Mariyam

6. Seluruh Dosen Pengajar yang sudah mendukung proses penyusunan skripsi ini dari awal hingg akhir.

7. Seluruh Mahasiswa Sarjana Keperawatan Angkatan XI Stikes Awalbros

\section{DAFTAR PUSTAKA}

Amriyati, A. 2016. Kinerja Perawat Ditinjau dari Lingkungan Kerja dan Karakteristik Individu (Studi pada Instansi Rawat Inap Rumah Sakit Umum Banyumas Unit Swadana Daerah. manajemen Pelayanan Kesehatan. Skripsi tidak dipublikasikan.

Awan, T. 2014. Pengaruh Kepemimpinan Transaksional Terhadap Motivasi Kerja Karyawan pada Kantor PT Wijaya Sukses Sejahtera di Kabupaten Berau, eJournal Administrasi Bisnis, Volume 2, Nomor 3, hal: 386-400.

Bijani, M et al. 2016. Factors influencing poor nursing documentation from the perspective of nursing staff. [online] htttp://ijmrhs.com. Diakses pada 30 Oktober 2019 pukul 19.00.

Darmastuti, A. 2015. Pengaruh Kepuasan Kerja Dan Motivasi Kerja Terhadap Prestasi Kerja Karyawan (Studi Pada Pt. Inti 
Luhur Fuja Abadi (Ilufa), Pasuruan). Skripsi tidak dipublikasikan.

Dasril, M. 2017. Analisis Fungsi Rewarddan

PunishmentTerhadap Motivasi Kerja Perawat Bagian Rawat Inap di RSUD Lubuk Basung Tahun 2017. Skripsi tidak dipublikasikan.

Fatmawati, A. 2016. Hubungan Pemberian Reward dengan Motivasi Kerja Perawat Pelaksana di Ruang Rawat Inap Kelas III RSUD RAA Soewondo Pati. [online] http://h ttp://eprints.ums.ac.id/44947/3/0 2.\%20NASKAH\%20PUBLIKA SI.pdf. Diakses pada 10 Februari 2020.

Febrianti, S. 2014. Pengaruh Reward dan Punishment Terhadap Motivasi Kerja Serta Dampaknya Terhadap Kinerja. Skripsi tidak dipublikasikan.

Hamzah, U. 2018. Teori Motivasi dan Pengukurannya, Jakarta : Bumi Aksara.

Hasibuan. 2014. Organisasi dan Motivasi. Jakarta: Bumi Aksara.

Hicks, G \& Gullet, R. 2016. Organisasi; Teori dan Tingkah Laku. Edisi Ketiga. Jakarta: Bumi Aksara.

Ivancevivh, J et al. 2016. Perilaku dan Manajemen Organisasi Jilid 1. Edisi Ketujuh. Jakarta: Erlangga.

Jaishwal, $\mathrm{P}$ et al. 2014. Level of motivation amongst health personnel working in a tertiary care government hospital of new delhi, India. Indian $\mathbf{J}$ Community Med. 2014 Oct;39(4):235-40.

Kadir, A. 2016. Pengaruh Kepuasan Pasien Terhadap Minat Menggunakan Jasa Pelayanan Keperawatan Di Ruang Rawat
Inap Rumah Sakit Umum Daerah Pangkap. Skripsi tidak dipublikasikan.

Kemkes RI. 2015. Profil Kesehatan Indonesia Tahun 2014. [on line]. https://www.depkes.go.id/ resources/download/pusdatin/pr ofil-kesehatan-indonesia/profilkesehatan-indonesia-2014.pdf. Diakses pada 30 Oktober 2019 pukul 19.00.

Lufitasari, R. 2014. Pengaruh Motivasi Kerja, Disiplin Kerja dan Kompensasi terhadap Kinerja Karyawan pada Dinas Pendapatan, Pengelolaan Keuangan dan Aset D.I Yogyakarta. Skripsi tidak dipublikasikan.

Mahmudi. 2015. Manajemen Kinerja Sektor Publik. Edisi Ketiga. Yogyakarta: UPP STIM YKPN.

Mallongi, A et al. 2018. The Factors Affecting Performance of Nurses at Sorong District Hospital. GaloreInternational Journal of HealthSciences and Research Vol.4; Issue: 1; Jan.March 2019.

Mangkunegara, A. 2017. Manajemen Sumber Daya Manusia Perusahaan. Bandung: Remaja Rosdakarya.

Marquis, B. L. \& Huston, C. J. 2010. Kepemimpinan dan manajemen keperawatan : teori dan aplikasi, (Ed. 4).Jakarta : EGC

Newel, B. Shanks, D. 2014. Unconscious Influences on Decision Making: A Critical Review. Behavioral and Brain Sciences 37: 1-61.

Novalia, R. 2017. Hubungan Reward Dan Punishment Dengan Motivasi Mengikuti Handover Perawat Di Ruang Rawat Inap Rumah Sakit Umum Daerah 
Dr.Zainoel Abidin Banda Aceh. Skripsi tidak dipublikasikan.

Nugroho, A. (2015). Pengaruh Reward Dan Punishment Terhadap Kinerja Karyawan PT Business Training And Empowering Management Surabaya, IV(2), 4-14. Jurnal Maksipreneur. Sekolah Tinggi Ilmu Ekonomi Mahardhika.

Nursalam. 2016. Metodologi Penelitian Ilmu Keperawatan: Pendekatan Praktis. Ed. 4. Jakarta: Salemba Medika.

Purwanto. 2014. Instrumen Penelitian Sosial dan Pendidikan. Yogyakarta: Pustaka Pelajar.

Rivai, V. Sagala, E. 2015. Manajemen Sumber Daya Manusia untuk Perusahaan. Jakarta: Raja Grafindo Persada.

Robbins, S. Judge, T. 2017. Perilaku Organisasi. Jakarta: Salemba Empat

Sandy, S. 2017. Pengaruh reward dan punishment serta rotasi pekerjaan terhadap motivasi kerja untuk meningkatkan kinerja karyawan hotel di jember. Jurnal Kepariwisataan dan Hospitalitas Vol. 1, No. 2, November 2017.

Sedarmayanti. 2014. Sumber Daya Manusia dan Produktivitas Kerja. Bandung: Mandar Maju

Seitovirta, J et al. 2018. Registered nurses' perceptions of rewarding and its significance. [online] file :///C:/Users/FUJITSU/AppData/ Local/Temp/Registered\%20nurs es'\%20perceptions\%20of\%20re warding\%20and $\% 20$ its $\% 20$ sign ificance. \%20-\%20PubMed\%20\%20NCBI.pdf. Diakses pada 30 oktober 2019 pukul 19.00.

Susanti, E. 2014. Pengaruh Reward Dan Punishment Terhadap Kinerja Karyawan Pada Pt. Ciomas Adisatwadi Sidoarjo. Jurnal Manajemen Branchmarck Vol 4, Issue 3.

Tangkuman, K. 2015. Penilaian Kinerja, Reward dan Punishment Terhadap Kinerja Karyawan Pada PT. Pertamina (PERSERO) cabang Sulawesi Utara Vol.3 No.2 Juni 2015, Hal. 884-895 (Hal 36).

Tongotongo, M dkk. 2017. Faktor Faktor Yang Berhubungan Dengan Motivasi Kerja Perawat di Unit Rawat Inap RSUD Tobelo Kabupaten Halmahera Utara Tahun 2017. Skripsi tidak diterbitkan.

Toode, K et al. 2015. Hospital nurses' work motivation. [online] file:///C:/Users/FUJITSU/AppD ata/Local/Temp/Hospital\%20nu rses'\%20work\%20motivation.\% $20 \% 20$ PubMed\%20\%20NCBI. pdf. Diakses pada 30 oktober 2019 pukul 19.00. 